\title{
Asymmetry in the ovary and uterus of the golden hamster (Mesocricetus auratus)
}

\author{
W. S. O and P. H. Chow \\ Department of Anatomy, University of Hong Kong, Hong Kong
}

\begin{abstract}
Summary. On Day 9 of pregnancy (day of mating = Day 1), the number of corpora lutea in the right ovary was greater than that in the left (mean \pm s.e.m. $9 \cdot 3 \pm 0 \cdot 1$ and $6.5 \pm 0.3$ respectively; $N=70$ ). Although the percentages of ova fertilized on the left and right side were not different $(82 \%$ and $94 \%)$, the percentage wastage was higher on the left side $(20 \%)$ than the right $(14 \%)$. A significant difference in sperm numbers in the right $\left(2.8 \times 10^{6}\right)$ and the left $\left(0.5 \times 10^{6}\right)$ uterine horns were found $1.5 \mathrm{~h}$ after mating in 51 females. Morphometric measurements of the lower uterine luminal size showed that the right side $\left(103.9 \mathrm{~mm}^{3}\right)$ was larger than the left side $\left(88.9 \mathrm{~mm}^{3} ; \mathrm{N}=5\right)$. It is obvious that there is structural and functional asymmetry in the ovary and uterus in the golden hamster.
\end{abstract}

\section{Introduction}

In the past two decades, there has been a great deal of research in reproduction involving the use of golden hamsters (Mesocricetus auratus). This has been reviewed in two monographs on hamsters (Hoffman et al., 1968; Siegel, 1985). During an investigation to study the fertility of the male hamster after operation (Chow \& O, 1985), we noticed that there is asymmetry in the function of the ovaries and uterus, and the data are reported in this paper.

\section{Materials and Methods}

Randomly bred golden hamsters (Mesocricetus auratus) were kept in the Laboratory Animal Unit, University of Hong Kong, under a $14 \mathrm{~h}$ light:10 h dark cycle (lights on from 01:00 to 15:00 h). All adult female hamsters were checked for at least two consecutive normal cycles before mating. The structure of the uterus was studied by dissection, as well as in longitudinal and transverse serial sections prepared after perfusion fixation.

Experiment 1: ovulation and embryo numbers. Female hamsters were mated on the day of pro-oestrus $1 \mathrm{~h}$ after the onset of darkness (Day 1), and were killed on Day 9. The numbers of corpora lutea in the left and the right ovaries were counted. The embryos in the left and right uterine horns counted in 15 animals and the embryos were dissected to check for normal development.

Experiment 2: sperm distribution in the uterus. Male and female hamsters were hand mated for $15 \mathrm{~min}$ at $1 \mathrm{~h}$ after darkness on the day of pro-oestrus. The females were killed $1.5 \mathrm{~h}$ after mating, and the female tract was ligated at the tubo-uterine junction, at the bifurcation of the two uterine horns and at the vagino-uterine junction. These various segments of the tract were dissected out and flushed with $1 \%$ Triton $\mathrm{X}-100$ in normal saline $(9 \mathrm{~g} \mathrm{NaCl} / \mathrm{l})$. The spermatozoa from each segment of the tract were diluted and counted with a haemocytometer.

Experiment 3: uterine luminal size. Five virgin adult female hamsters were killed on Day 2 and perfused arterially with phosphate-buffered formo-saline $\left(100 \mathrm{ml} 40 \%\right.$ formaldehyde, $9 \mathrm{~g} \mathrm{NaCl}, 6.5 \mathrm{~g} \mathrm{Na}_{2} \mathrm{HPO}_{4}, 4 \mathrm{~g} \mathrm{NaH}_{2} \mathrm{PO}_{4} \cdot \mathrm{H}_{2} \mathrm{O}$ in $900 \mathrm{ml}$ distilled water). The uteri were dissected out, post-fixed in the same fixative, processed and serially sectioned at $15 \mu \mathrm{m}$. The luminal size of the lower uterus was measured on alternate sections at $\times 13$ magnification using an Apple digitising tablet. The cranial end of the lower uterus was demarcated by a line drawn between the point of appearance of the longitudinal muscle layer. The lower limit of the uterine lumen was at a line drawn between the lowest point of the uterine septum and the endo-exocervical junction.

The luminal volume of the left and the right sides was calculated by the summation of the measured luminal area $\times 2 \times 15 \mu \mathrm{m} \times$ number of measured sections. 
Statistical analysis. Comparisons of the numbers of corpora lutea, embryos and spermatozoa and the uterine luminal sizes on the right and left sides were made using paired Student's $t$ tests. The numbers of ova fertilized and the wastage on the left and right sides were compared by $\chi^{2}$ tests.

\section{Results}

The structure of the hamster uterus was found to be similar to that of the rat as described by Deanesly (1938). The horns of the uterus fused to form an undivided segment. The uterine lumina were separated by a wedge-shaped median septum. The two uterine lumina fused to form a single cavum uteri at about $1 \mathrm{~mm}$ above the external os which opened posteriorly. The left and the right uterine horns were therefore clearly separated to a great extent and migration of embryos from one side to the other would be very unlikely.

\section{Experiment 1: ovulation and embryo numbers}

The numbers of corpora lutea and embryos found on the left and the right sides of the tract are summarized in Table 1. The right ovary of the female golden hamster ovulated significantly more ova than did the left ovary. There was no difference in the percentages of ova fertilized on the two sides but the percentage wastage was higher on the left side than on the right.

Table 1. The numbers (mean \pm s.e.m.) of corpora lutea and of embryos in the left and right uterine horns of Day 9 pregnant hamsters

\begin{tabular}{lcccc}
\hline & $\begin{array}{c}\text { No. of } \\
\text { animals }\end{array}$ & \multicolumn{1}{c}{ Left } & \multicolumn{1}{c}{ Right } & Significance \\
\hline Corpora lutea & 70 & $6.5 \pm 0.3$ & $9 \cdot 3 \pm 0.1$ & $P<0.001$ \\
$\begin{array}{l}\text { Embryos in uterus } \\
\text { \% ova fertilized }\end{array}$ & 15 & $5.8 \pm 0.8$ & $9 \cdot 2 \pm 1.9$ & $P<0.001$ \\
\% dead embryos/ & 15 & $82.2 \pm 7.5$ & $94.0 \pm 1.6$ & $P<0.1$ \\
fertilized ova & 15 & $28.5 \pm 9.2$ & $14.1 \pm 4.7$ & $P<0.01$ \\
\hline
\end{tabular}

Experiment 2: sperm distribution

In 51 hamsters, there were $47.4 \pm 1.9 \times 10^{4}$ spermatozoa in the left uterine horn and $289.0 \pm 1.7 \times 10^{4}$ spermatozoa in the right uterine horn $(P<0.001)$.

\section{Experiment 3: uterine luminal size}

The extensive, labyrinthine foldings in the upper uterine endometrium made accurate measurement of the lumen difficult, and so only the lower uterine luminal size on each side was measured in 5 hamsters. The right lower uterine lumen $\left(103.9 \pm 10.5 \mathrm{~mm}^{3}\right)$ was larger than that on the left $\left(88.9 \pm 9.3 \mathrm{~mm}^{3}\right)(P<0.05)$.

\section{Discussion}

Uterine asymmetry associated with asymmetry of ovarian function has been reported in five bovid species (see Rowlands \& Weir, 1984), some families of bats (Wimsatt, 1979) and small North American mammals (Baird \& Birney, 1985). Three of the North American cricetid rodents, the 
same family to which the golden hamster belongs, also showed such asymmetric ovarian function. However, asymmetry in reproductive structures and function in common laboratory species has not been reported previously. In golden hamsters, we have found that the right ovary ovulates more ova than the left side. It is not clear what the cause of this asymmetry could be.

The site of semen deposition in the hamster is in the uterus, as it is in the rat, mouse, pig and cow. We found large number of spermatozoa in the uterus after mating, confirming the report by Yamanaka \& Soderwall (1960). The difference in ovulation rate on the two sides could perhaps explain the asymmetry of the sperm distribution in the uterine horns and the different uterine sizes. With more follicles maturing and more corpora lutea formed on the right side, the ovarian hormones carried by the ovarian vein/lymphatic vessels might exert a greater influence on the ipsilateral uterine horn. The ovarian hormones may directly affect sperm transport in the female tract or may affect the uterine luminal size to allow a wider passage for spermatozoa. An interrelationship of the ovarian and uterine functional asymmetry has been demonstrated in cow, sheep and guinea-pig: the countercurrent system of the uterine and ovarian blood and/or lymph vessels carries prostaglandin F-2 $\alpha$ to the corpora lutea of the corresponding side (for review, see Findlay, 1983).

Although there was no difference in the fertilization rate of the ova on the two sides, there seemed to be a higher percentage of wastage on the left than on the right side. The wastage found in our experiments appeared to be reasonably low compared with reported values from other rodents (see Carr, 1977).

Based on ovulation, embryo numbers and morphometry of the uterine lumina, our results show that there is an asymmetry in ovarian and uterine function in the golden hamster. This asymmetry should be carefully considered in the design of any experiments using golden hamsters, especially when the contralateral side of the reproductive tract is used as a control.

We thank Miss May P. L. Cheung and Mr U. L. Lui for assistance. The experiments were supported by the Hong Kong University Grant (No. 335/031/0013) and the Medical Faculty Research Grant Fund, Hong Kong University (No. 311/030/8040/39).

\section{References}

Baird, D.D. \& Birney, E.C. (1985) Bilateral distribution of implantation sites in small mammals of 22 North American species. J. Reprod. Fert. 75, 381-392.

Carr, D.H. (1977) Detection and evaluation of pregnancy wastage. In Handbook of Teratology, Vol. 3, pp. 189-213. Eds J. G. Wilson \& F. C. Fraser. Plenum Press, New York.

Chow, P.H. \& O, W.S. (1985) Sperm distribution, fertilization, embryonic development and the male accessory sex glands in the golden hamster. Proc. $12 \mathrm{th} \mathrm{Int}$. Anat. Congr. London Abstr. A116.

Deanesly, R. (1938) The reproductive cycle of the golden hamster (Cricetus auratus). Proc. zool. Soc. Lond. A 108, 31-37.

Findlay, J.K. (1983) The endocrinology of the implantation period. In Current Topics in Endocrinology, Vol. 4, The Endocrinology of Pregnancy and Parturition, pp. 36-67. Eds L. Martini \& V. H. T. James. Academic Press, London.
Hofiman, R.A., Robinson, P.F. \& Magalhaes, H. (Eds) (1968) The Golden Hamster, its Biology and Uses in Medical Research. Iowa University Press, Ames.

Rowlands, I.W. \& Weir, B.J. (1984) Mammals: nonprimate Eutherians. In Marshall's Physiology of Reproduction, 4th edn, Vol. 1, pp. 455-658. Ed. G. E. Lamming. Churchill Livingstone, London.

Siegel, H.I. (1985) The Hamster, Reproduction and Behaviour. Plenum Press, New York.

Wimsatt, W.A. (1979) Reproduction asymmetry and unilateral pregnancy in Chiroptera. J. Reprod. Fert. 6, 345-357.

Yamanaka, H.S. \& Soderwall, A.L. (1960) Transport of spermatozoa through the female genital tract of hamsters. Fert. Steril. 11, 470-474.

Received 4 June 1986 